\title{
A ordem do discurso escolar
}

\author{
Luís Henrique Sommer
}

Universidade Luterana do Brasil, Programa de Pós-Graduação em Educação

\section{Introdução}

A produção educacional recente é pródiga em investigações que vão privilegiar análises de discurso inspiradas na obra de Michel Foucault. Em Palamidessi (1996), por exemplo, temos acesso às formas como a identidade do professor construtivista é produzida no discurso curricular argentino nos anos de 1970. Em Gvirtz (1999) encontramos uma brilhante análise de cadernos de alunos, abarcando um período de 40 anos (entre os anos de 1930 e os primeiros anos da década de 1970). Em sua investigação, a autora toma os cadernos enquanto um dispositivo escolar, "como um conjunto de práticas discursivas escolares que se articulam de um determinado modo produzindo um efeito" (p. 14, tradução livre). Em outras palavras, trata-se de tomar o caderno "como produtor dos saberes escolares” (p. 15, tradução livre). Destaco ainda os trabalhos de Garcia (2000), que faz uma análise dos discursos pedagógicos críticos, como instituidores de modos de subjetivação e individualização específicos, destacando seu caráter pastoral-disciplinar; Bujes (2002) e sua análise dos dispositivos de gover- namento da infância, isolados no texto do Referencial Curricular Nacional para a Educação Infantil (RCNEI); e Xavier (2003), que, além de incursionar pela pesquisa etnográfica, toma elementos de uma análise de discurso foucaultiana na medida em que também analisa práticas discursivas eminentemente escolares, materializadas em fichas, relatórios de avaliação e dossiês na escola fundamental. Pode-se dizer que todos esses trabalhos compartilham certa compreensão acerca da centralidade dos discursos na produção de práticas sociais e subjetividades.

O presente artigo inscreve-se na moldura teóricometodológica da produção anteriormente listada e pretende problematizar determinados conceitos que circulam na escola fundamental nos últimos anos, e que, no meu entendimento, estão implicados no ordenamento de nossas salas de aula e na regulação das práticas docentes. O texto consiste em uma análise de um conjunto de dados referente à primeira etapa de uma pesquisa que está escutando professoras da Região Metropolitana de Porto Alegre que atuam na escola pública de ensino fundamental, além de estudantes do curso de pedagogia de uma universidade 
da mesma região. A referida pesquisa orienta-se pela hipótese de que há certa ordem do discurso escolar. Quer dizer, há determinadas regras que sancionam ou interditam a produção e a circulação de práticas discursivas escolares. Ao mesmo tempo, a circulação, a disseminação, o compartilhamento de certos enunciados que compõem essas práticas discursivas estão implicados na produção das identidades das professoras, nas suas formas de enxergar a sala de aula, os alunos, a educação, enfim, na própria materialização da educação escolar, na operação de práticas nãodiscursivas, ${ }^{1}$ especialmente no ensino fundamental.

Como já foi expresso, a abordagem teóricometodológica toma contribuições de uma análise de discurso de inspiração foucaultiana. Para este trabalho, considerarei corpus de análise as falas de dez professoras de escolas públicas da região mencionada. As professoras entrevistadas têm entre 22 e 36 anos e atuam na rede pública municipal de duas das cidades que compõem o campo empírico da pesquisa. Três delas têm formação em nível médio (magistério), quatro são graduadas em pedagogia e as outras três estão cursando pedagogia. Nenhuma delas está exercendo a função de coordenação pedagógica, ainda que, entre aquelas que são licenciadas em pedagogia, uma tenha habilitação em supervisão escolar e três em orientação escolar. Para a coleta de dados, utilizei a técnica da entrevista semi-estruturada.

\section{Definições: práticas discursivas escolares e análise de discurso}

É preciso fazer uma distinção preliminar entre práticas discursivas escolares e práticas discursivas pedagógicas. Segundo Gvirtz (1999, p. 15, tradução

${ }^{1}$ Aqui entendidas como formas de se comportar, de agir, de atuar, que vão além da atuação docente. Refiro-me ao disciplinamento dos corpos e mentes, à interiorização da disciplina que faz com que cada um vigie a si próprio. Tal ideal e tais efeitos são discutidos em profundidade por Foucault (1996) em Vigiar e punir. livre), "as primeiras se distinguem destas últimas na medida em que se considera que são produções da escola, e as segundas seriam produções sobre a escola, ou seja, conformariam metadiscursividades na medida em que seriam práticas discursivas (as pedagógicas) que se referem a outras práticas discursivas". Nesse sentido, podemos definir como práticas discursivas pedagógicas, por exemplo, a ampla produção acadêmica no campo da educação que focaliza a escola, nas mais diferentes perspectivas teóricas e metodológicas, os enunciados do discurso didático, das metodologias etc. Em contrapartida, seriam exemplos de práticas discursivas escolares o caderno do aluno, o boletim, o quadro de giz, as falas de alunos e de professoras.

A opção por uma análise de discurso de inspiração foucaultiana envolve considerar uma série de precauções propostas pelo filósofo, a começar pelo estabelecimento de uma distinção, qual seja, a de que a noção de discurso rompe com os sentidos correntes do campo da lingüística, calcados no binarismo significante-significado e em "uma oposição dicotômica entre os fenômenos da língua - social - e da fala - individual" (Palamidessi, 1996, p. 192, tradução livre). Nesses termos, rejeita-se todo um conjunto de pressupostos lingüísticos que têm implicado o estabelecimento da noção de discurso como realizações da fala de um sujeito produtor de significados.

Em Foucault, os discursos são práticas organizadoras da realidade. Ainda que feitos de signos, "o que fazem é mais que utilizar esses signos para designar coisas. É esse mais que os torna irredutíveis à língua e ao ato da fala" (Foucault, 2000, p. 56, grifos do original). Os discursos estabelecem hierarquias, distinções, articulam o visível e o dizível. Quer dizer, o foco não estaria "no significado das palavras, mas sim no papel do discurso nas práticas sociais" (idem, p. 193, tradução livre), no papel dos discursos na organização das relações entre indivíduos, instituições e organizações sociais mais amplas.

As chaves para o desenvolvimento de uma análise de discurso, eu as encontrei na célebre aula inaugural que Foucault proferiu no Collège de France em 
2 de dezembro de 1970: A ordem do discurso. Nesse texto, que pode ser considerado o limiar de sua "fase" genealógica, ele marca um deslocamento em seu método de pesquisa. Se até então o filósofo empenhavase, por exemplo, em analisar o aparecimento dos saberes constitutivos do que viria a ser paradigmatizado como as ciências humanas, a partir de condições de possibilidade internas aos próprios saberes, desde $A$ ordem do discurso ele vai introduzir o poder como "instrumento de análise capaz de explicar a produção dos saberes" (Machado, 1998, p. X). Assim, nessa obra, Foucault vai centrar-se na relação entre as práticas discursivas e os poderes que a atravessam, demonstrando que existem diversos procedimentos que controlam e regulam a produção dos discursos em nossas sociedades. Em suas próprias palavras:

[...] em toda sociedade a produção do discurso é ao mesmo tempo controlada, selecionada, organizada e redistribuída por certo número de procedimentos que têm por função conjurar seus poderes e perigos, dominar seu acontecimento aleatório, esquivar sua pesada e temível materialidade. [...] Sabe-se bem que não se tem o direito de dizer tudo, que não se pode falar de tudo em qualquer circunstância, que qualquer um, enfim, não pode falar de qualquer coisa. (Foucault, 1998a, p. 8-9)

É sabido que a obra na qual se encontra mais detalhado o processo de análise de enunciados, ou o que Fischer (2001a, 2001b) tem chamado de teoria do discurso de Foucault, é A arqueologia do saber, em que são apresentadas exaustivamente as noções de discurso, enunciado, as relações entre práticas discursivas e não-discursivas, formação discursiva, enfim, as ferramentas utilizadas para uma descrição arqueológica. Entretanto, meu trabalho não está centrado em uma análise das bases epistemológicas da produção do discurso (Rago, 1995); antes, procuro explorar a produtividade de determinadas práticas discursivas escolares, entre elas a sua capacidade de ordenar os espaços e tempos do ensinar e do aprender.

Levando em conta todas essas precauções, o esquema da entrevista com as professoras girava em torno dos tópicos: papel da escola, papel do professor, quem são nossos alunos, organização das aulas e conceito de alfabetização. Tais focos foram definidos, por um lado, em função de meu exercício profissional no ensino fundamental, por aproximadamente 15 anos. Por outro lado, a minha atuação na formação de professoras em dois cursos de pedagogia, nos últimos três anos, indicou-me que essas questões poderiam ser centrais para compreendermos as atuais configurações da escola fundamental brasileira, cuja trajetória recente revela uma quase total incapacidade de prover as crianças de competências e habilidades até pouco tempo consideradas essenciais, como, por exemplo, a leitura e a escrita.

É preciso deixar claro que, orientando minha investigação, está a hipótese de que as práticas discursivas da escola obedecem a um ordenamento prévio, que os enunciados obedecem a regras de formação específicas, que alguns ditos são sancionados e outros interditados. Enfim, que o que se diz na escola somente repercute porque é referendado por uma ordem mais ampla, porque está na ordem do discurso. Palavras na educação, o uso de algumas delas e a "proibição" do uso de outras tantas, este é, pode-se dizer, o foco de minha investigação; procurar compreender a produção na escola, o efetivamente feito, a partir do que pode e do que não pode ser dito:

[...] o que é afinal um sistema de ensino senão uma ritualização da palavra [fala]; senão uma qualificação e uma fixação de papéis para os sujeitos que falam; senão a constituição de um grupo doutrinário ao menos difuso; senão uma distribuição e uma apropriação do discurso com seus poderes e seus saberes? (Foucault, 1998a, p. 44-45)

Antes de entrar, propriamente, na descrição e análise dos dados, faço mais um esclarecimento de natureza teórico-metodológica: tomo os discursos como monumentos, o que implica operar sobre os ditos, sobre a superfície dos textos, sem buscar um suposto significado subjacente à sua materialidade; eles terão sentido a partir de sua exterioridade, e não a partir da lógica interna dos seus enunciados. Assu- 
mo, pois, de antemão, a negativa de qualquer tentativa de extrair dos textos o que é "mesmo" que os sujeitos dos discursos queriam dizer, mas reafirmo a lógica de "estabelecer as relações entre esses enunciados e aquilo que eles descrevem" (Veiga-Neto, 1996, p. 185). Nesse sentido, em momento algum me perguntei o que, exatamente, as professoras estavam querendo dizer, no que elas realmente acreditavam, qual era o substrato epistemológico de suas concepções. Pelo contrário, empenhei-me em deixá-las falar, justamente porque me interessava descrever os efeitos de verdade de determinadas práticas discursivas, do uso de um determinado conjunto de palavras que não são em si verdadeiros ou falsos. Nesse ponto, procurei seguir outra precaução de Foucault (1998b, p. 7), para quem "o problema não é de se fazer a partilha entre o que um discurso revela de cientificidade e da verdade e o que revelaria de outra coisa; mas de ver historicamente como se produzem efeitos de verdade no interior de discursos que não são em si nem verdadeiros nem falsos". Ou, fazendo uso das palavras de Gore (1994, p. 10), "minha intenção é assinalar uma preocupação não tanto com o que as palavras significam quanto com a forma como as palavras, conjuntos de sentenças e práticas relacionadas funcionam".

Na continuação deste trabalho, procedo às análises propriamente ditas. Nesse processo, considerei que as regularidades e as raridades enunciativas estão em relevo e, como tal, merecem ser comentadas, discutidas à luz do pensamento foucaultiano e confrontadas com as produções de autores que têm tematizado alguns dos aspectos extraídos das falas das entrevistadas.

\section{A escola: autonomia, criticidade, cidadania}

[...] a escola é a instituição responsável pela formação integral dos alunos. Ela tem a função de preparar para a vida, de contribuir para a formação de sujeitos autônomos e críticos que façam a diferença, que sejam capazes de transformar a sociedade. Olha, eu acho que, mais do que passar um monte de conteúdos, a escola precisa se preocupar em socializar as crianças, em fazer com que elas aprendam re- gras de convivência e que desenvolvam a consciência crítica. Aí, quando elas saírem daqui elas vão poder ocupar um espaço, sabendo o que são direitos e o que são deveres. É mais ou menos isto que está na nossa filosofia e é nisso que eu acredito. Acho que nós todas acreditamos porque a gente construiu a filosofia em grupo, nosso projeto políticopedagógico foi muito discutido [...]. A gente tem dúvidas, todo mundo tem, mas o grupo sabe o que não quer ser: uma escola conteudista, uma escola tradicional. A gente quer fazer a diferença na vida de nossas crianças, que eles sejam cidadãos, que eles saiam cidadãos conscientes. Para se conseguir isto, precisamos fazer da escola um ambiente de liberdade, de valorização das diferenças individuais. $(\mathrm{P} 1)^{2}$

Essa transcrição é emblemática de uma compreensão que as professoras compartilham acerca do papel da escola. De certa forma, ela sintetiza o pensamento de todas as entrevistadas. Os ideais de autonomia, criticidade e cidadania são facilmente identificados nas falas, eu ousaria dizer, do magistério em geral. O que chama a atenção não são exatamente esses conceitos, mas a interdição de outros. Ao mesmo tempo em que se privilegia a formação moral, encapsulada na aprendizagem de regras de convivência, nota-se que a palavra "ensino" não é contemplada. A escola não é definida como um lugar de ensinar, é um lugar de aprender a comportar-se (regras de convivência, socialização). As dúvidas que o grupo compartilha são amenizadas à medida que se explicita o que a escola não quer ser: conteudista, tradicional. Quer dizer, de certa forma o que sou se define pelo que não sou, pelo que não quero ser. A fala da entrevistada convida para outras discussões: a função da escola é produzir sujeitos autônomos e críticos, mas tal produção se dá pela socialização controlada, pelo aprendizado de regras de convivência.

As práticas pedagógicas, postas em operação desde o alvorecer da escola moderna, são indissociá-

${ }^{2}$ A partir deste ponto, utilizo o código P1, P2, que se referem à Professora 1 , à Professora 2 etc., para demarcar as falas das professoras entrevistadas preservando suas identidades. 
veis da idéia de disciplina enquanto "distribuição dos conhecimentos em categorias hierarquizadas" (VeigaNeto, 2001, p. 46) e enquanto "disciplinarização “em termos de atitudes, comportamentos hábitos etc. " que é exigida às crianças e jovens, na escola, em nome de sua boa e mais fácil aprendizagem" (idem, p. 47). Em outras palavras, historicamente a escola pode ser vista como locus de aplicação de tecnologias disciplinares, que se dão em dois eixos complementares: o eixo corporal e o eixo dos saberes. A interdição da palavra ensino, a negativa em ensinar conteúdos e o privilégio atribuído à formação moral, atitudinal, não seriam sintomas de um esmaecimento no eixo disciplina-saber e um fortalecimento no eixo disciplina-corpo. Quer dizer, esse postulado espaço de liberdade e de valorização das diferenças não redundaria em maior controle, em um disciplinamento mais efetivo dos corpos, na medida em que se privilegia essa formação moral? Haveria um flagrante deslocamento na noção de escola enquanto instituição produtora de sujeitos disciplinados, capazes de autogovernaremse, como tem sido desde sua gênese, ou esse pretenso espaço de liberdade, essas novas configurações dos espaços e tempos da escola (por exemplo, a escola ciclada) não revelariam, justamente, um maior controle dos corpos, na medida em que mais e mais crianças permaneceriam mais tempo encerradas nessa instituição? Essas são algumas das discussões que o tema nos convida a fazer.

\section{0 professor: organizador, condutor, mediador da aprendizagem}

No que se refere ao papel do professor, as opiniões também são convergentes. A noção de professor como "organizador do ambiente de aprendizagem" (P3), como "responsável por administrar as aprendizagens dos alunos" (P5), como "aquela que garante a produção de aprendizagens significativas" (P2), como "alguém que conduz os alunos em seu processo de construção do conhecimento" (P4), como "mediador da aprendizagem dos alunos" (P7), como alguém que "atenda as necessidades dos educandos"
(P10) denota a regulação do discurso escolar por saberes de um mesmo campo epistemológico. Ainda que minha análise não se volte para um exame das bases epistemológicas da ação docente, vale destacar o compartilhamento de uma mesma matriz, qual seja, a construtivista, desde alguns anos hegemônica da escola fundamental brasileira. Aqui, aprendizagem é a palavrachave. Nas práticas discursivas que enunciam o papel do professor, mais uma vez a palavra ensino está interditada. Talvez, no entendimento das professoras, a noção de ensino esteja muito matizada, muito comprometida com a noção de escola tradicional, com a idéia de transmissão de conhecimentos. Em contrapartida, a noção de aprendizagem é algo tacitamente aceito, não discutido, assim como as palavras mediação, construção de conhecimentos, aprendizagens significativas.

Neste ponto vale destacar as contribuições de Cappelletti (2000) acerca do que ela denomina fetichização do discurso da didática. Ancorada nas contribuições de Freud e Bourdieu, respectivamente sobre fetiche e campo intelectual, a autora vai demonstrar a regularidade de certas palavras-chave no discurso didático, de forma que este

[...] se apresenta como uma estrutura lingüística formal sem conteúdo real, de onde se configura uma semântica própria: "conteúdo socialmente significativo", "conhecimento compartilhado", [...] "pesquisa-ação", "mediação", "saberes prévios", e outras expressões que circulam no âmbito do discurso didático, que correntemente se utilizam sem precisar seu significado. $\mathrm{O}$ uso destes termos se generaliza de modo irreversível através de seu uso em textos legitimados por sua origem (textos oficiais, ou elaborados por centros de pesquisa) ou pelo status acadêmico de seus autores. Esta generalização de expressões fetichizadas, que não chegam a ser plenamente precisadas ou inteiramente compreendidas, coloca o discurso didático em risco de converter-se em uma linguagem que não diz nada. (p. 205, tradução livre)

É preciso destacar que a autora não faz uma análise de práticas discursivas escolares, mas peda- 
gógicas, nem opera a partir do referencial teórico que baliza minha pesquisa. Entretanto, uma vez que propõe uma forma de desconstrução de uma prática discursiva pedagógica - o discurso didático - que é, por definição, endereçado às professoras, consumido nos espaços escolares, há uma aproximação temática, pode-se mesmo dizer de enfoque, posto que se trata de colocar sob suspeita certas expressões, certas palavras que as professoras do ensino fundamental têm usado para pensar. Palavras que definem os (im)precisos limites de suas práticas pedagógicas. O que estou tentando apontar é que o uso de alguns conceitos, de determinadas palavras, e não de outras, produzem efeitos específicos. Para a autora citada, a imprecisão conceitual, a polifonia semântica do discurso didático implica a impossibilidade de construir qualquer prática pedagógica, uma vez que ela estaria fundada "em um discurso vazio de conteúdo real" (idem, p. 212, tradução livre).

\section{Aluno: criança essencializada}

O aluno produzido pelos discursos escolares harmoniza-se perfeitamente ao apregoado papel do professor enunciado: "é um sujeito biopsicossocial responsável pela sua própria aprendizagem" (P2), "ele passa por determinadas etapas que devem ser levadas em conta pela professora na organização da aula" (P8), "é alguém que fica inteligente na medida em que aprende" (P6), "não existe aluno que não aprenda. Na verdade, sempre há um crescimento, uma evolução. É claro que a gente deve avaliar cada um em relação a ele mesmo" (P10), "claro, as crianças estão diferentes, sabe como é, a mídia. A mídia hoje tem um poder muito forte. Às vezes a gente não sabe bem como lidar com isso. Mas, sem dúvida, elas aprendem de forma muito parecida. É preciso respeitar as características de cada fase, de cada idade" (P3), "acho que hoje o aluno traz muitas coisas da sua realidade, e nós temos que partir disto que os alunos sabem, valorizar o que eles sabem. Eles estão sempre aprendendo" (P1).
De forma geral, as professoras comungam da crença em uma criança essencializada, que passa pelas mesmas etapas na direção de seu desenvolvimento. Mais uma vez a matriz do campo psicológico regula as asserções das professoras acerca de seus alunos. Ao que parece, as produções de Ariès (1981) e Narodowski (1994), entre tantos outros que demonstram a historicidade e a produção cultural da infância, não têm grandes repercussões no cotidiano da escola. Na verdade, pode-se afirmar que persiste a imagem da criança universal, a-histórica e determinada biológica e psicologicamente. Tal como aponta Bujes (2003), em pesquisa que examinou currículos de cursos de formação de professores, há a predominância dessa noção de criança como seres em desenvolvimento "de base biológica, seqüenciado em etapas, prolongando-se por toda a vida, envolvendo dimensões cognitivas, sócio-afetivas e psicomotoras, ainda que se dando num todo indissociável" (p. 13, grifos do original). Nessa mesma lógica, aprofundando os efeitos dessa noção de criança, Sommer (2004, p. 29) vai afirmar que "esta representação de criança natural, em contínuo (e 'natural') processo de desenvolvimento, é princípio e fim da organização didático-pedagógica da sala de aula, isto é, das práticas dos professores e professoras" das classes de alfabetização brasileiras.

Enfim, pode-se inferir que os sentidos da função docente, o entendimento acerca da função do professor e, por extensão, as suas práticas pedagógicas "estão totalmente saturadas com a noção de uma seqüência normalizada de desenvolvimento da criança, de forma que aquelas práticas ajudam a produzir a criança como objeto do seu olhar" (Walkerdine, 1998, p. 145). Em outras palavras, as ações das professoras são condicionadas por certa infância-referência, por uma imagem cristalizada de criança que é produto de discursos do campo da psicologia cujos efeitos vão além da pura descrição de como as crianças são, mas que, de fato, acabam estabelecendo o que se faz, e como se faz, no espaço da sala de aula. Os efeitos de verdade de tais discursos acabam por obliterar a capacidade das professoras de falarem sobre seu pró- 
prio trabalho. Tudo que elas formulam parece obedecer a certas regras postas por essa categoria fundante, por essa representação estandardizada de infância, de aluno.

\section{O rganização das aulas: organização do espaço}

Quando o tema da discussão é a organização das aulas, a imensa maioria faz menção às atividades em grupo: "olha, eu sempre prefiro que eles trabalhem em grupo, por duas razões: primeiro, acho que dividir a sala de aula em grupo é uma forma mais democrática de trabalho, menos tradicional; e, em segundo lugar, as trocas entre os alunos exigem que eles considerem a opinião do outro, e isto faz com que eles superem o egocentrismo, e cada um acaba ajudando o outro" (P3); "acho que esta história de classes [carteiras] uma atrás da outra é coisa do passado. Tá mais que provado que as crianças aprendem melhor umas com as outras. Mesmo aquele que tem dificuldades acaba sendo ajudado pelos colegas que terminam as tarefas primeiro" (P9); "eu penso que a escola tem que fazer sentido para as crianças, tem que considerar os seus desejos, os seus interesses, a escola é deles, é pra eles. Então, se tu observares o comportamento das crianças na hora do recreio tu vais notar que elas, naturalmente, se organizam em grupos. Então, por que não trabalhar em grupos na sala de aula? E depois, certamente esta é uma forma mais democrática de organizar a sala de aula" (P6).

É importante destacar que, ao focalizar a organização das aulas nas entrevistas, eu tinha por objetivo compreender mais do que as formas como as professoras organizam o espaço da sala de aula. Eu esperava que elas informassem as particularidades de suas atuações docentes; que fosse possível, entre outros aspectos, extrair suas visões de metodologia, de planejamento; enfim, que elas falassem como ensinam. Apenas uma das entrevistadas usou a palavra ensino, e para afirmar que a escola precisa "mudar o foco do ensino para a aprendizagem, mudar o foco dos conteúdos e dos métodos para as formas como as crianças aprendem" (P3). Na verdade, ela apenas re- pete uma máxima do discurso pedagógico construtivista. Quantos de nós, pesquisadores da educação, não escutamos esse lema pedagógico, ou mesmo o repetimos, desde o final dos anos de 1980? Ensino, metodologia, didática, planejamento são conceitos interditados, estão fora da ordem do discurso escolar. Outro aspecto que chama a atenção consiste no vínculo entre democracia e natureza infantil. Dito de outra forma, entre pedagogias críticas e pedagogias psicológicas. Essa conexão foi explorada por Silva (1998, p. 7), para quem "no Brasil, os projetos educacionais, as reformas curriculares e os programas de treinamento e formação docente de administrações municipais lideradas pelos mais diversos partidos parecem ter sido homogeneizados por uma mesma pedagogia que se poderia chamar de psicocrítica: técnicas psi movidas por impulsos libertários".

Para Gore (1994), em contrapartida, existe uma política da verdade na educação contemporânea, ${ }^{3} \mathrm{o}$ que envolve a aceitação tácita de discursos do campo

[...] da Psicologia e vinculados a noções particulares de ciência [...]; a razão científica tem sido o meio principal pelo qual estes discursos são sancionados; as técnicas empíricas têm tido primazia na produção da verdade; tem-se concedido um status profissional, científico e intelectual àqueles que estão encarregados de dizer o que conta como verdade. (p. 10)

No que se refere ao ordenamento das salas de aula, a autora demonstra, por exemplo, que a disposição das classes em círculo (prática comum nas séries finais do ensino fundamental, no ensino médio e na universidade) pode implicar maior controle, uma vez que se amplia o campo de visibilidade e de vigilância dos alunos. Quer dizer, se na sala de aula organizada em fileiras, em tese, cada aluno é supervisionado ape-

\footnotetext{
${ }^{3}$ Apesar de Jennifer Gore centrar-se no estudo dos regimes
} de verdade dos discursos pedagógicos na Austrália, são notáveis as similaridades com a realidade brasileira. 
nas pela professora, existindo um espaço de invisibilidade, ao menos parcial, que se concretiza no esconder-se atrás do colega sentado na frente, na disposição por círculo todos são sempre visíveis, alcançáveis pelo olhar da professora e pelo olhar de cada um dos colegas. Nas palavras da autora, "o círculo pode exigir das [dos] estudantes uma maior autodisciplina, pela qual elas [eles] assumem a responsabilidade por comportar-se 'apropriadamente' sem o 'olhar' da professora" (Gore, 1994, p. 16). O que a autora acaba demonstrando em sua análise é que não há nada de inerentemente libertador ou repressor nas diferentes formas de organizar a sala de aula.

\section{Alfabetização: processo contínuo...}

O conceito de alfabetização consiste em outra quase unanimidade: "é um processo contínuo que vai muito além da primeira série" (P5); "é a leitura do mundo, é a capacidade de compreender e agir para transformar" (P2); "é muito mais do que decodificar, é compreender a vida" (P10); "não é um processo mecânico de se entender um código, é muito mais do que isso, alfabetização é compreensão" (P8); "é uma aquisição de um conceito, de uma idéia, um processo onde as crianças são sujeitos ativos, formulando hipóteses sobre a leitura e a escrita" (P3); "alfabetização é um direito de todos, mas é preciso respeitar o tempo de cada um. Algumas crianças não se alfabetizam na primeira série, mas nem por isso elas devem ser reprovadas. A professora da série seguinte deve continuar trabalhando a alfabetização do ponto em que a criança se encontra" (P6); "a alfabetização dura a vida toda, não se restringe à primeira série e nem se restringe à escola" (P7); "olha, eu acho que temos que pensar que alfabetização não é pura e simples decodificação, e sim compreensão, mas não podemos esquecer que a escrita é um código e, como tal, no processo de alfabetização a gente precisa ensinar os significados deste código. Olha, podem me chamar de tradicional, mas a primeira coisa que eu trabalho é $\mathrm{o}$ alfabeto, o nome e o som das letras. Acho que isto é a matéria-prima da alfabetização" (P1).
Com exceção desta última entrevistada, percebe-se o compartilhamento de uma visão difusa acerca da alfabetização, pelo menos no que se refere às responsabilidades da professora nesse processo. Notese que apenas uma professora fala em ensinar significados de um código, e mesmo assim com a ressalva de que pode ser vista como "tradicional". Todas as outras ora privilegiam a noção de alfabetização como leitura do mundo (tradição freireana), ora refutam a idéia de codificação. Além disso, salta aos olhos a noção de alfabetização como um processo individual, na medida em que é preciso respeitar os ritmos próprios de cada criança, e os sentidos libertários do ser alfabetizado (alfabetizar-se para compreender e mudar o mundo).

Os sentidos expressos pelas professoras acerca do conceito de alfabetização podem ser interpretados à luz das contribuições de Soares (2004, p. 8-9), para quem temos presenciado uma "perda de especificidade da alfabetização", o que estaria redundando na desinvenção da alfabetização, na escola pública brasileira. Para a autora, "a causa maior dessa perda de especificidade da alfabetização [...] deve ser buscada em fenômeno mais complexo: a mudança conceitual a respeito da aprendizagem da língua escrita que se difundiu no Brasil a partir de meados dos anos 1980" (p. 9). Sem negar as inegáveis contribuições que uma perspectiva psicogenética ${ }^{4}$ pode trazer à educação, Soares aponta que, ao privilegiar a dimensão psicológica da alfabetização, isto é, o processo de apropriação/construção do sistema de escrita pela criança, se preteriu a dimensão lingüística (fonética e fonológica) da alfabetização. Além disso, ainda segundo a mesma autora, outro equívoco consiste na suposta incom-

${ }^{4}$ Em sua análise, Soares (2004) vai discutir a emergência e consolidação do paradigma teórico cognitivista no campo da alfabetização, nos Estados Unidos e no Brasil. Para ela, no Brasil, os anos de 1980 e 1990 caracterizam-se pela hegemonia desse paradigma, que aqui se teria difundido como construtivismo e, mais tarde, socioconstrutivismo. 
patibilidade entre uma perspectiva psicogenética e a noção de método de alfabetização:

[...] o fato de que o problema da aprendizagem da leitura e da escrita tenha sido considerado, no quadro dos paradigmas conceituais "tradicionais", como um problema sobretudo metodológico contaminou o conceito de método de alfabetização, atribuindo-lhe uma conotação negativa: é que, quando se fala em "método" de alfabetização, identifica-se, imediatamente, "método" com os tipos "tradicionais" de métodos - sintéticos e analíticos (fônico, silábico, global etc.), como se esses tipos esgotassem todas as alternativas metodológicas para a aprendizagem da leitura e da escrita. Talvez se possa dizer que, para a prática da alfabetização, tinha-se, anteriormente, um método, e nenhuma teoria; com a mudança de concepção sobre o processo de aprendizagem da língua escrita, passou-se a ter uma teoria, e nenhum método. (Soares, 2004, p. 11)

Por último, Soares (2004) vai apontar uma confusão entre letramento e alfabetização. A afirmação categórica de que as crianças vão alfabetizar-se pelo puro e simples contato corriqueiro e intenso com materiais escritos, com práticas de letramento, colocaria em segundo plano a noção de "alfabetização, como processo de aquisição do sistema convencional de uma escrita alfabética e ortográfica" (idem, p. 11).

\section{Considerações finais}

Ao longo deste artigo, penso ter demonstrado a presença de certas regularidades nos discursos da professoras entrevistadas. Quer dizer, de certa forma pode-se afirmar que elas utilizam palavras muito parecidas para pensar a educação, a função do professor, o aluno, a sala de aula, a alfabetização. Mais do que usar significantes comuns, do que se trata é dos sentidos, dos significados que tais palavras assumem. Talvez se possa dizer que há um aprisionamento dos sujeitos dos discursos escolares, de forma que, ao utilizarem tais palavras, o que pode ser pensado obedece aos limites que os significados particulares que elas assumem em nossa época permitem. Nesse sentido, pode-se inferir as razões por que certas palavras são proibidas, interditadas, tais como método, ensino, didática: elas não pertencem mais a esta época, elas pertencem a outra tradição, elas estão fora de ordem do discurso.

Talvez tenha sido Jorge Larrosa quem melhor conseguiu traduzir essa conexão inextrincável entre palavras e experiência, o que, no meu entendimento, se harmoniza perfeitamente com meu objeto de análise neste texto:

As palavras determinam nosso pensamento porque não pensamos com pensamentos, mas com palavras, não pensamos a partir de uma suposta genialidade ou inteligência, mas a partir de nossas palavras. E pensar não é somente "raciocinar" ou "calcular" ou "argumentar", como nos tem sido ensinado algumas vezes, mas é sobretudo dar sentido ao que somos e ao que nos acontece. E isto, o sentido ou o sem sentido, é algo que tem a ver com as palavras. E, portanto, também tem a ver com as palavras o modo como nos colocamos diante de nós mesmos, diante dos outros e diante do mundo em que vivemos. E o modo como agimos em relação a tudo isso. (Larrosa, 2002, p. 21)

Ainda que a amostra analisada nessa pesquisa não me autorize a fazer grandes generalizações acerca do ensino fundamental brasileiro, ao menos posso estabelecer algumas novas relações, levantar algumas outras perguntas. Por exemplo, se o que eu expus neste artigo se aplicar a boa parte das professoras que atuam no ensino fundamental, não passariam por aí as razões de $55 \%$ dos estudantes brasileiros das $4{ }^{\text {as }}$ séries desse ensino estarem nos níveis "muito crítico" e "crítico", no que se refere às competências em língua portuguesa, como indicam os resultados do último Sistema Nacional de Avaliação da Educação Básica) (SAEB)? ${ }^{5}$ De fato, pode-se falar que existe um desajuste entre o que se diz e o que se faz em educação? Dito de outra forma, será que as professoras do

${ }^{5}$ Fonte: Brasil, Ministério da Educação. Resultados do Saeb 2003. Brasília: jun. 2004. Versão preliminar. 
ensino fundamental poderiam ensinar quando, no limite, as suas práticas discursivas obedecem a um ordenamento prévio que interdita a palavra ensino? Será que elas poderiam ensinar a ler e a escrever, quando alfabetização é definida como leitura do mundo, e codificação de fonemas e decodificação de grafemas estão fora da ordem do discurso escolar?

Enfim, apesar de reconhecer os limites deste trabalho, acredito que ele aponta algumas pistas para entendermos o que estamos fazendo em nossas salas de aula do ensino fundamental público brasileiro. No meu entendimento, não se pode afirmar que existe alguma contradição entre o dito e o feito em nossas escolas. O que se faz é condicionado pelo que se diz e, nesse sentido, o estado atual do ensino fundamental deste país harmoniza-se com as palavras autorizadas, com as palavras permitidas, sancionadas pela ordem do discurso escolar.

\section{Referências bibliográficas}

ARIÈS, Philippe. História social da criança e da família. 2. ed. Trad. Dora Flaksman. Rio de Janeiro: Guanabara, 1981.

BUJES, Maria I. E. Infância e maquinarias. Rio de Janeiro: DP\&A, 2002.

. Crianças de manual. In: SEMINÁRIO DE PESQUISA POLÍTICAS DA SUBJETIVIDADE E PRÁTICAS DE DIFERENÇA EM EDUCAÇÃO, 1., 2003, Pelotas. Anais... Pelotas: UFPEL, 2003. p. 1-15. 1 CD-ROM.

CAPPELLETTI, Graciela. El fetichismo y la didáctica. Educação \& Realidade, v. 25, n. 1, p. 201-213, dez.-jan./jun. 2000.

FISCHER, Rosa M. B. Uma análise foucaultiana da tv: das estratégias de subjetivação na cultura. In: REUNIÃO ANUAL DA ANPEd, 24., 2001, Caxambu. Anais... Caxambu: ANPEd, 2001a. 1 CD-ROM.

. Foucault e a análise do discurso em educação. $\mathrm{Ca}$ dernos de Pesquisa, n. 114, p. 197-223, nov. 2001b.

FOUCAULT, Michel. Vigiar e punir: nascimento da prisão. 14. ed. Trad. Raquel Ramalhete. Petrópolis: Vozes, 1996.

. A ordem do discurso: aula inaugural no Collège de

France, pronunciada em 2 de dezembro de 1970. Trad. Laura F. A. Sampaio. Campinas: Loyola, 1998a.
Verdade e poder. In: Microfísica do poder. 13. ed. Org. e trad. Roberto Machado. Rio de Janeiro: Graal, 1998b. p. 1-14.

. A arqueologia do saber. 6. ed. Trad. Luiz F. B. Neves. Rio de Janeiro: Forense-Universitária, 2000.

GARCIA, Maria M. A. A função pastoral-disciplinar das pedagogias críticas. 2000. 155f. Tese (Doutorado em Educação) - Faculdade de Educação, Universidade Federal do Rio Grande do Sul, Porto Alegre, 2000.

GORE, Jennifer M. Foucault e educação: fascinantes desafios. In: SILVA, Tomaz T. (Org.). O sujeito da educação: estudos foucaultianos. Petrópolis: Vozes, 1994. p. 9-20.

GVIRTZ, Silvina. El discurso escolar a través de los cuadernos de clase: Argentina 1930-1970. Buenos Aires: Eudeba, 1999.

LARROSA, Jorge. Notas sobre a experiência e o saber da experiência. Revista Brasileira de Educação, n. 19, p. 20-28, jan./abr. 2002.

MACHADO, Roberto. Introdução: por uma genealogia do poder. In: FOUCAULT, Michel. Microfísica do poder. 13. ed. Org. e trad. Roberto Machado. Rio de Janeiro: Graal, 1998. p. vii-xxiii.

NARODOWSKI, Mariano. Infancia y poder: la conformación de la pedagogía moderna. Buenos Aires: Aique, 1994.

PALAMIDESSI, Mariano I. La producción del "maestro constructivista" en el discurso curricular. Educação \& Realidade, v. 21, n. 2, p. 191-213, jul./dez. 1996.

RAGO, Margareth. O efeito-Foucault na historiografia brasileira. Tempo Social, n. 7, p. 67-82, out. 1995.

SILVA, Tomaz T. As pedagogias psi e o governo do eu nos regimes neoliberais. In: (Org.). Liberdades reguladas: a pedagogia construtivista e outras formas de governo do eu. Petrópolis: Vozes, 1998. p. 7-13.

SOARES, Magda. Letramento e alfabetização: as muitas facetas. Revista Brasileira de Educação, n. 25, p. 5-17, jan./abr. 2004.

SOMMER, Luís H. Construtivismo: a ordem discursiva das classes de alfabetização brasileiras. A Página da Educação, n. 139, p. 29 , nov. 2004.

VEIGA-NETO, Alfredo. A ordem das disciplinas. 1996. Tese (Doutorado em Educação) - Faculdade de Educação, Universidade Federal do Rio Grande do Sul, Porto Alegre,1996.

Regulação social e disciplina. In: SCHMIDT, Saraí (Org.). A educação em tempos de globalização. Rio de Janeiro: DP\&A, 2001. p. 45-48. 
WALKERDINE, Valerie. Uma análise foucaultiana da pedagogia construtivista. In: SILVA, Tomaz T. (Org.). Liberdades reguladas: a pedagogia construtivista e outras formas de governo do eu. Petrópolis: Vozes, 1998. p. 143-216.

XAVIER, Maria L. M. F. Os incluídos na escola: o disciplinamento nos processos emancipatórios. 2003. Tese (Doutorado em Educação) - Faculdade de Educação, Universidade Federal do Rio Grande do Sul, Porto Alegre, 2003.

LUÍS HENRIQUE SOMMER, doutor em educação pela Universidade Federal do Rio Grande do Sul, é professor do curso de pedagogia e do mestrado em educação da Universidade Luterana do Brasil. Últimas publicações: Tomando palavras como lentes (in: COSTA, Marisa V.; BUJES, Maria I. E. (Orgs.). Caminhos investigativos III: riscos e possibilidades de pesquisar nas fronteiras. Rio de Janeiro: DP\&A, 2005. p. 69-83); com Marisa V. Costa, A pedagogia da cultura e a educação de crianças e jovens do ensino fundamental (in: LEHENBAUER, Silvana; PICAWY, Maria M.; STEYER, Vivian E.; WANDSCHEER, Maria S. (Orgs.). $O$ ensino fundamental no século XXI: questões e desafios. Canoas: ULBRA, 2005. p. 63-74). Projeto de pesquisa em desenvolvimento: "Sanções e interdições do discurso pedagógico contemporâneo". E-mail: henriquesommer@uol.com.br

Recebido em novembro de 2005 Aprovado em outubro de 2006 


\section{Resumos/Abstracts/Resumens}

\section{Luís Henrique Sommer}

\section{A ordem do discurso escolar}

Este artigo toma elementos de uma análise de discurso foucaultiana e examina práticas discursivas escolares que circulam na escola fundamental. Tratase de problematizar certos conceitos, certas regularidades enunciativas, e demonstrar sua implicação no ordenamento de nossas salas de aula e na regulação das práticas docentes. $\mathrm{O}$ trabalho é orientado pela hipótese de que há certa ordem do discurso escolar. Isto é, há determinadas regras que sancionam e/ou interditam a produção e a circulação de práticas discursivas escolares. Ao mesmo tempo, a circulação, a disseminação, o compartilhamento de certos enunciados que compõem essas práticas discursivas têm efeitos na produção das identidades das professoras, nas suas formas de enxergar a sala de aula, os alunos, a educação, enfim, na própria materialização da educação escolar. Os dados analisados neste trabalho foram obtidos por meio de entrevis- tas, feitas com professoras de ensino fundamental da rede pública de duas cidades do Rio Grande do Sul. Ao analisar a ordem do discurso escolar, aponto a harmonia existente entre o dito e o feito na escola pública de ensino fundamental.

Palavras-chave: educação fundamental; análise de discurso; Michel Foucault

\section{The order of school discourse}

This article takes elements of a Foucaultian analysis of discourse and examines discursive practices which circulate in elementary schools. Its purpose is to problematise certain concepts and certain enunciatory regularities and to demonstrate their implication for ordering our classrooms and for regulating teachers' practices. This work is based on the hypothesis that there is a kind of ordering in school discourse. That is, that there are certain rules that sanction and/or interdict the production and circulation of school discursive practices. At the same time, the circulation, the dissemination, the sharing of certain enunciations that make up these discursive practices have effects on the production of teachers' identities, on their ways of looking at the classroom, the students, education, in short, on the very materialisation of school education. The data analysed in this article was obtained through interviews, carried out with teachers at public elementary schools in two cities in the state of Rio Grande do Sul. When analysing the order of school discourse, I point to the existing harmony between what is said and done in public elementary school education.

Key words: elementary education; analysis of discourse; Michel Foucault

\section{El orden del discurso escolar}

Este artículo toma elementos de un análisis de discurso foucaultiana e axamina prácticas discursivas escolares que circulan en la escuela fundamental. Se trata de problematizar ciertos conceptos, ciertas regularidades enunciativas y demostrar su 
implicación en el ordenamiento de nuestras salas de clase y en la regulación de las prácticas docentes.

El trabajo es orientado por la hipótesis de que hay un cierto orden del discurso escolar. O sea, hay determinadas reglas que sancionan y/o impiden la producción y la circulación de prácticas discursivas escolares. Al mismo tiempo, la circulación, la diseminación, la división de ciertos enunciados que componen estas prácticas discursivas tienen efectos en la producción de las identidades de las profesoras, en sus formas de ver la sala de clase, los alumnos, la educación, en fin, en la propia materialización de la educación escolar. Los datos analisados en este trabajo fueron obtenidos a través de entrevistas, hechas con profesoras de enseñanza fundamental de la red pública de dos ciudades de Río Grande del Sur. Al analisar el orden del discurso escolar, apunto la harmonía que existe entre lo dicho y lo hecho en la escuela pública de enseñanza fundamental

Palabras claves: educación fundamental; análisis de discurso; Michel

Foucault 